\title{
Correlates and Predictors of Increasing Waist Circumference in Patients with Type 2 Diabetes Mellitus: A Cross-Sectional Study
}

\author{
Victor Mogre, ${ }^{1}$ Robert Abedandi, ${ }^{2}$ and Zenabankara S. Salifu ${ }^{2}$ \\ ${ }^{1}$ Department of Human Biology, School of Medicine and Health Sciences, University for Development Studies, Tamale, Ghana \\ ${ }^{2}$ Department of Allied Health Sciences, School of Medicine and Health Sciences, University for Development Studies, Tamale, Ghana \\ Correspondence should be addressed to Victor Mogre; vmogre@uds.edu.gh
}

Received 28 April 2014; Revised 18 June 2014; Accepted 26 June 2014; Published 15 September 2014

Academic Editor: José María Huerta

Copyright (c) 2014 Victor Mogre et al. This is an open access article distributed under the Creative Commons Attribution License, which permits unrestricted use, distribution, and reproduction in any medium, provided the original work is properly cited.

\begin{abstract}
Type 2 diabetes mellitus (type $2 \mathrm{DM}$ ) has become a disease of public health concern worldwide. Obesity and elevated blood pressure have been shown to be comorbidities of type 2 DM. In this cross-sectional study in Tamale, Ghana, we determined the prevalence of abdominal obesity among type $2 \mathrm{DM}$ patients. Furthermore, we examined the demographic, clinical, and anthropometric predictors of increasing waist circumference in this population. Three hundred type $2 \mathrm{DM}$ patients attending the outpatient diabetes clinic of the Tamale Teaching Hospital, Ghana, were recruited for the study. Waist circumference (WC) and hip circumferences were measured appropriately. Systolic blood pressure (SBP) and diastolic blood pressure (DBP) and fasting plasma glucose (FPG) were taken from the personal health record files of patients. Demographic data were obtained. Pearson correlation and multiple linear regression models were employed to identify predictors of increasing WC. The prevalence of abdominal obesity was $77.0 \%$ and was significantly higher in women than in men. A positive correlation was observed between waist-to-hip ratio (WHR) and WC $(r=0.56, P<0.001)$, female gender $(r=0.73, P<0.001)$, and age $(r=0.20, P<0.001)$. A high prevalence of abdominal obesity was observed. Predictors of increasing WC were gender, age, FPG, and WHR.
\end{abstract}

\section{Background}

Diabetes especially diabetes mellitus (DM) has become a disease of concern for both developed and developing countries $[1,2]$. In adults, the prevalence of DM worldwide was estimated to be $8.3 \%$ in 2011 and is expected to rise to $9.9 \%$ by the year 2030 [3] largely due to the global obesity epidemic and other factors [4]. A DM prevalence of $8 \%$ has been reported in Europe and the US $[5,6]$. In subSaharan Africa the prevalence of diabetes has not been well established [7]. Reported prevalence varies widely (Benin 3\%; Mauritania 6\%; Cameroon 6.1\%; Congo 7.1\%; Zimbabwe 10.2\%; Democratic Republic of Congo 14.5\%) [8]. Type 2 diabetes mellitus (type $2 \mathrm{DM}$ ) has been shown to be the most common form of diabetes in sub-Saharan Africa $[9,10]$ constituting $90-95 \%$ [11]. At least $6 \%$ of adults in Ghana are affected with type $2 \mathrm{DM}[12]$.

Type $2 \mathrm{DM}$ has been shown to be associated with obesity [12]. Abdominal obesity/central obesity measured by either waist circumference (WC) or waist-to-hip ratio (WHR) has been shown to be strongly associated with diabetes and other chronic diseases than general obesity measured by BMI [1315]. It is established that abdominal obesity is associated with decreased glucose tolerance, alterations in glucose insulin homeostasis, reduced metabolic clearance of insulin, and decreased insulin-stimulated glucose disposal [13]. Some $31 \%$ of adults in Tamale, Ghana, are centrally obese and this has been related to advanced age, low physical activity, female gender, urban environment, high income, distorted perception of weight status, and tertiary education [12,16-21].

With contrasting prevalence, severe complications, and public health significance, a study on the prevalence of abdominal obesity and its predictors in type $2 \mathrm{DM}$ patients are remarkably scarce. Understanding the burden of abdominal obesity and its associated factors is pertinent in guiding diagnosis, management, and prevention of DM in subSaharan Africa.

The objective of this study was to determine the prevalence of abdominal obesity (measured by WC) in a sample of type 2 DM patients. Furthermore, we examined the 
demographic, clinical, and anthropometric determinants of increasing waist circumference in this same sample.

\section{Materials and Methods}

2.1. Participants. Three hundred (300) previously diagnosed diabetes patients attending the diabetes clinic of the Tamale Teaching Hospital in Tamale, Ghana, were recruited for this cross-sectional study in 2013. As described elsewhere [21], all previously diagnosed diabetes patients that sought for care from the Hospital's diabetes clinic, during the study period, were eligible to participate in the study. Three hundred and twenty-one participants were approached; 300 of them consented to the study, yielding a response rate of $93.5 \%$. Informed consent was obtained from all the study participants. The study was approved by the Ethics Committee of the University for Development Studies, School of Medicine and Health Sciences, Ghana.

2.2. Inclusion Criteria. Participants aged $\geq 30$ years, who have clinical determined type 2 DM based on the WHO criteria [22], and who have duration of diabetes of at least 1 year were qualified to participate in the study.

2.3. Exclusion Criteria. Participants aged $<30$ years and pregnant and lactating mothers were excluded from the study. Also participants with a history of heart failure, type 1 DM, myocardial infarction, acromegaly, hypothyroidism, hypogonadism, and any other chronic diseases, patients on prolonged steroid use, and those who were on active drug treatment for obesity at the time of admission were excluded from the study.

2.4. Anthropometric Parameters. Anthropometric measurements of waist and hip circumferences were taken. Waist circumference (WC) was measured midway between the inferior angle of the ribs and the suprailiac crest [23]. Hip circumference was measured as the maximal circumference over the buttocks in centimetres. Both measurements were measured to the nearest $1 \mathrm{~cm}$ using a nonstretchable fibre-glass measuring tape (Butterfly, China). During both measurements, participants stood in an upright position, with arms relaxed at the side, feet evenly spread apart, and body weight evenly distributed in accordance with the WHO expert consultation report on waist circumference and waist-to-hip ratio [23]. Abdominal obesity was determined as a waist circumference $>102 \mathrm{~cm}$ in men and $>88 \mathrm{~cm}$ in women according to the World Health Organization cut-off points and risk of metabolic complications for waist circumference [23].

2.5. Clinical Parameters. Clinical variables such as systolic blood pressure (SBP) and diastolic blood pressure (DBP) and fasting plasma glucose (FPG) values were taken from the personal health record files of the diabetic patients. Elevated blood pressure denoted a mean $\mathrm{BP} \geq 140 / 90 \mathrm{mmHg}$ and/or documented antihypertensive treatment [24]. Impaired fasting glycaemia (IFG) was defined as FPG $\geq 6.1 \mathrm{mmoll}^{-L}$ [22]. Hyperglycaemia was determined by a FPG $\geq 7.0$ [22].
IFG and hyperglycaemia were combined to denote uncontrolled diabetes. Sociodemographic data such as gender, age, and duration of diabetes were also obtained from the patients.

2.6. Statistical Analysis. All data were entered into Microsoft Excel 2007 and analysed using GraphPad Prism version 5 (GraphPad software, San Diego, California, USA, http://www.graphpad.com) and the PASW statistics 18 for Windows. Data are expressed as mean and SD. Continuous data were analyzed using Student's $t$-test whilst categorical variables were analyzed using Fisher's exact test using GraphPad Prism version 5. Pearson correlation coefficient was used to test the relationship among the various parameters. A Forward:LR method of multiple linear regression models was used to determine the predictors of WC. All correlation and multiple linear regression analyses were done using PASW statistics 18 for Windows. In all statistical tests, a value of $P<0.05$ was considered significant.

\section{Results}

Presented in Table 1 are the general characteristics of the study population.

Mean waist circumference was found to be $95.99 \mathrm{~cm}$ and significantly higher in women than in men. The prevalence of abdominal obesity was found to be $77.0 \%$ and significantly higher in women than in men $(P<0.001)$. Average systolic blood pressure (SBP) and diastolic blood pressure (DBP) of the participants were $122.8 \pm 16.16 \mathrm{mmHg}$ and $84.5 \pm$ $13.83 \mathrm{mmHg}$. Men had higher mean SBP $(P=0.015)$ and $\operatorname{DBP}(P=0.001)$ than women. Over $70 \%$ of both men and women were found to have uncontrolled diabetes. Among the participants with uncontrolled diabetes, $29.9 \%(n=69)$ had impaired fasting glycaemia and 70.1\% $(n=162)$ had hyperglycaemia. Significantly $(P=0.008)$, the mean age of the women $(57.22 \pm 12.32$ years $)$ in this study was higher than men $(52.83 \pm 10.85$ years $)$.

The mean duration of diabetes among the participants was found to be $5.23 \pm 5.00$ years in which men had a higher mean duration than women.

As seen in Table 2, there were significant positive correlations between WHR and WC, gender, and age. Significantly, WC correlated positively with WHR $(r=0.56, P<0.01)$, age $(r=0.50, P<0.01)$, and gender $(r=0.36, P<0.01)$.

The multiple linear regression models in Table 3 show the relative contribution of predictor variables of WC. Explaining $14 \%$ of the variance in WC in Step 1, gender was a significant predictor of WC. In Step 2, gender was no longer a significant predictor of WC, but WHR $(b=0.43, P<0.01)$, age ( $b=0.40, P<0.01)$, and FPGL $(b=0.14, P<0.01)$ were significant predictors of WC. The model explained $48 \%$ of the variance in predicting WC. DD did not significantly predict WC.

\section{Discussion}

This cross-sectional study from Tamale, Ghana, among type $2 \mathrm{DM}$ patients attending an outpatient clinic shows a high 
TABLE 1: Anthropometric and clinical measurements of the study population stratified by gender.

\begin{tabular}{|c|c|c|c|c|}
\hline Variable & $\begin{array}{c}\text { Total } \\
(n=300)\end{array}$ & $\begin{array}{c}\text { Men } \\
(n=69)\end{array}$ & $\begin{array}{c}\text { Women } \\
(n=231)\end{array}$ & $P$ value \\
\hline $\mathrm{WC}(\mathrm{cm})$ & $95.99 \pm 15.61$ & $85.17 \pm 13.93$ & $99.22 \pm 14.63$ & $<0.001$ \\
\hline \multicolumn{5}{|l|}{ Abdominal obesity } \\
\hline Yes & $231(77.0 \%)$ & $18(26.1 \%)$ & $213(92.2 \%)$ & \multirow{2}{*}{$<0.001$} \\
\hline No & $69(23.0 \%)$ & $51(73.9 \%)$ & $18(7.8 \%)$ & \\
\hline WHR & $0.94 \pm 0.20$ & $0.71 \pm 0.06$ & $1.00 \pm 0.18$ & $<0.001$ \\
\hline $\mathrm{SBP}(\mathrm{mmHg})$ & $122.8 \pm 16.16$ & $127 \pm 12.04$ & $121.6 \pm 17.02$ & 0.015 \\
\hline $\mathrm{DBP}(\mathrm{mmHg})$ & $84.5 \pm 13.83$ & $88.26 \pm 11.75$ & $83.38 \pm 14.23$ & 0.001 \\
\hline \multicolumn{5}{|l|}{ Elevated BP } \\
\hline Yes & $57(19.0 \%)$ & $21(30.4 \%)$ & $36(15.6 \%)$ & \multirow{2}{*}{0.008} \\
\hline No & $243(81.0 \%)$ & $48(69.6 \%)$ & $195(84.4 \%)$ & \\
\hline Age (years) & $56.21 \pm 12.12$ & $52.83 \pm 10.85$ & $57.22 \pm 12.32$ & 0.008 \\
\hline$\leq 40$ years & $33(11.0 \%)$ & $12(17.4 \%)$ & $21(9.1 \%)$ & \multirow{2}{*}{0.077} \\
\hline$>40$ years & $267(89.0 \%)$ & $57(82.6 \%)$ & $210(90.9 \%)$ & \\
\hline FPG $($ Mean \pm SD $)$ & $7.94 \pm 2.81$ & $8.07 \pm 2.76$ & $7.9 \pm 2.83$ & 0.653 \\
\hline Uncontrolled diabetes (\%) & $231(77.0 \%)$ & $51(73.9 \%)$ & $180(77.9 \%)$ & 0.516 \\
\hline IFG (\%) & $69 / 231(29.9 \%)$ & $18 / 51(35.3 \%)$ & $51 / 180(28.3 \%)$ & \multirow{2}{*}{0.387} \\
\hline Hyperglycaemia (\%) & $162 / 231(70.1 \%)$ & $33(47.8 \%)$ & $129 / 180(71.7 \%)$ & \\
\hline Duration (years) & $5.23 \pm 5.00$ & $6.37 \pm 4.9$ & $4.88 \pm 4.97$ & 0.030 \\
\hline$\leq 5$ years & $198(66.0 \%)$ & $39(56.5 \%)$ & $159(68.8 \%)$ & \multirow{2}{*}{0.062} \\
\hline$>5$ years & $102(34.0 \%)$ & $30(43.5 \%)$ & $72(31.2 \%)$ & \\
\hline
\end{tabular}

IFG: impaired fasting glycaemia.

TABLE 2: Pearson correlation coefficient of the study parameters $(n=$ $300)$.

\begin{tabular}{lccccc}
\hline Variable & WHR & WC & AG & FPG & DD \\
\hline Gender (GE) & $\mathbf{0 . 7 3}^{* *}$ & $\mathbf{0 . 3 6}^{* *}$ & $0.15^{* *}$ & -0.01 & $-0.16^{* *}$ \\
WHR (WHR) & & $\mathbf{0 . 5 6}^{* *}$ & $0.21^{* *}$ & 0.01 & 0.06 \\
WC (WC) & & & $\mathbf{0 . 5 0}^{* *}$ & 0.05 & -0.01 \\
Age (AG) & & & & $-0.33^{* *}$ & 0.01 \\
FPG (FPG) & & & & & -0.02 \\
\hline
\end{tabular}

${ }^{* *}$ Correlation is significant at the 0.01 level (2-tailed). WHR: waist-to-hip ratio; WC: waist circumference; AG: Age; FPG: fasting plasma glucose; and DD: diabetes duration.

prevalence of central obesity and a relatively low prevalence of elevated blood pressure. Parameters that significantly predicted increasing waist circumference were gender, age, FPG, WHR, and WC.

Evidently, the prevalence of abdominal obesity was found to be $77.0 \%$. This is higher than the central obesity prevalence of $31.2 \%$ reported among an apparently healthy population of civil servants in Tamale, Ghana [18]. Our findings however concur with the central obesity prevalence of $75 \%$ in a hospital-based study of diabetes patients in Kumasi, Ghana [12], and 68.1\% among diabetes patients in Southern India [25]. This is not surprising since obesity has been shown to be a significant risk factor for diabetes especially in type 2 DM $[13,14]$.
The prevalence of elevated BP was found to be $19.0 \%$ in this diabetic population. This is lower than the $63.0 \%$ reported among diabetes patients in Kumasi, Ghana [12], $54.2 \%$ among diabetes patients in Benin City, Nigeria [26], $66.4 \%$ in a Cameroonian type 2 diabetic population [27], and $50 \%$ of the diabetes patients in Kenya [28]. The differences could be due to variations in definitions of hypertension, population characteristics, and ethnic variations [29].

In a univariate analysis, females were severalfold at risk of developing abdominal obesity. This was confirmed by our correlation and multiple linear regression models in which the female gender strongly predicted WHR and WC in a positive direction. Several studies have reported findings that are in agreement with the association between the female gender and obesity among diabetics [30-33]. A similar relationship has also been reported in cross-sectional studies among apparently healthy populations $[18,34-36]$.

In identifying factors that influenced WC, our correlation and multiple linear regression models revealed WHR, age, and FPG as independent predictors of WC in a positive direction. As reported in several studies, a positive relationship was found between age and WC making age a strong predictor of WC $(\beta=0.40,95 \% \mathrm{CI}=0.40-0.64, P<0.01)[12,37-39]$.

In agreement with our findings, WC significantly predicted the levels of blood glucose in a cross-sectional study in a sample of 5,882 adults from the US 1999-2004 National Health and Nutrition Examination Survey [40]. In a population-based survey of the prevalence of diabetes and correlates in an urban slum in a community in Nairobi, 
TABLE 3: Multiple linear regression predicting waist circumference $(n=300)$.

\begin{tabular}{|c|c|c|c|}
\hline Variable & $B(\mathrm{SE})$ & $\beta$ & $95 \%$ CI \\
\hline \multicolumn{4}{|l|}{ Step 1} \\
\hline (Constant) & $85.17(1.74)$ & & $81.75-88.60$ \\
\hline Female gender & $14.04(1.99)$ & $0.38^{* *}$ & $10.14-17.95$ \\
\hline \multicolumn{4}{|l|}{ Step 2} \\
\hline (Constant) & $36.56(8.94)$ & & $18.98-54.14$ \\
\hline Male versus female & $1.86(1.99)$ & 0.05 & $-2.05-5.77$ \\
\hline WHR & $33.59(4.24)$ & $0.43^{* *}$ & $25.25-41.93$ \\
\hline Duration & $-0.020(0.14)$ & -0.01 & $-0.29-0.25$ \\
\hline Age (years) & $0.52(0.06)$ & $0.40^{* *}$ & $0.40-0.64$ \\
\hline $\mathrm{FPG}(\mathrm{m} / \mathrm{mol})$ & $0.75(0.24)$ & $0.14^{*}$ & $0.27-1.23$ \\
\hline
\end{tabular}

$R^{2}$ for Step $1=0.14$, Step $2=0.48(P<0.001) .{ }^{* *} P<0.001,{ }^{*} P<0.05$. WHR: waist-to-hip ratio; WC: waist circumference; AG: age; FPG: fasting plasma glucose; and DD: diabetes duration.

Kenya, Ayah et al. found that persons with diabetes were twice as likely to have an elevated WC (OR 2.3; 95\% CI 1.2$4.6 \%$ ) and WHR (OR 2.1; 95\% 1.1-3.9\%) [41]. Increased intraabdominal adipose tissue is the most clinically relevant type of body fat that is associated with metabolic complications and adverse health effects including hyperinsulinemia and type 2 DM [42-44]. This indicates the negative influence of increasing WC on blood glucose levels. In the management of diabetes to maintain blood glucose levels, emphasis should be placed on regularly measuring and monitoring abdominal and central adiposity using a simple and inexpensive measure like WC [45].

Our findings should be considered in light of the following limitations. This was a cross-sectional study design that could not establish causality. FPG and blood pressure values were obtained secondarily from the personal health files of the diabetes patients. Although all care was taken to record the values to minimize errors, misreporting might have occurred. In addition, the sample size was not well distributed in terms of gender. Women were significantly higher than men; this affects the representativeness of the sample.

\section{Conclusion}

A high prevalence of central obesity was found. Predictors of increasing WHR and WC were the female gender, age, and FPG. A relatively low prevalence of elevated blood pressure was found.

\section{Conflict of Interests}

The right of the authors to examine, analyze, and publish the data of the research is not infringed upon by any contractual agreement or conflict of interests.

\section{Authors' Contribution}

Victor Mogre performed the analysis and interpretation of data, drafting of the paper, and critical revision of the paper.
Zenabankara S. Salifu was responsible for concept and design and Robert Abedandi was responsible for data acquisition.

\section{Acknowledgments}

The authors wish to thank Dr. Baba Sule, Lecturer, Department of Human Biology, School of Medicine and Health Sciences, UDS, for his professional guidance and encouragement during the writing of this paper. The authors also wish to thank the Metropolitan Director and the Nutrition Officer of the Tamale Metropolitan Health Directorate for making the anthropometric instruments for the data collection available to them.

\section{References}

[1] H. King, R. E. Aubert, and W. H. Herman, "Global burden of diabetes, 1995-2025: prevalence, numerical estimates, and projections," Diabetes Care, vol. 21, no. 9, pp. 1414-1431, 1998.

[2] H. King and M. Rewers, "Global estimates for prevalence of diabetes mellitus and impaired glucose tolerance in adults," Diabetes Care, vol. 16, no. 1, pp. 157-177, 1993.

[3] N. Unwin, D. Whiting, L. Guariguata, G. Ghyoot, and D. Gan, Eds., Diabetes Atlas, International Diabetes Federation, Brussels, Belgium, 5th edition, 2011.

[4] J. P. Boyle, A. A. Honeycutt, K. M. V. Narayan et al., "Projection of diabetes burden through 2050: impact of changing demography and disease prevalence in the U.S," Diabetes Care, vol. 24, no. 11, pp. 1936-1940, 2001.

[5] P. Passa, "Diabetes trends in Europe," Diabetes/Metabolism Research and Reviews, vol. 18, supplement 3, pp. S3-S8, 2002.

[6] J. S. Skyler and C. Oddo, "Diabetes trends in the USA," Diabetes/Metabolism Research and Reviews, vol. 18, supplement 3, pp. S21-S26, 2002.

[7] D. Beran and J. S. Yudkin, "Diabetes care in sub-Saharan Africa," The Lancet, vol. 368, no. 9548, pp. 1689-1695, 2006.

[8] J. C. N. Mbanya, A. A. Motala, E. Sobngwi, F. K. Assah, and S. T. Enoru, "Diabetes in sub-Saharan Africa," The Lancet, vol. 375, no. 9733, pp. 2254-2266, 2010.

[9] G. V. Gill, J.-C. Mbanya, K. L. Ramaiya, and S. Tesfaye, "A subSaharan African perspective of diabetes," Diabetologia, vol. 52, no. 1, pp. 8-16, 2009. 
[10] N. S. Levitt, "Diabetes in Africa: epidemiology, management and healthcare challenges," Heart, vol. 94, no. 11, pp. 1376-1382, 2008.

[11] V. C. Tuei, G. K. Maiyoh, and C. Ha, "Type 2 diabetes mellitus and obesity in sub-Saharan Africa," Diabetes/Metabolism Research and Reviews, vol. 26, no. 6, pp. 433-445, 2010.

[12] I. Danquah, G. Bedu-Addo, K. Terpe et al., "Diabetes mellitus type 2 in urban Ghana: characteristics and associated factors," BMC Public Health, vol. 12, no. 1, article 210, 2012.

[13] G. Vazquez, S. Duval, D. R. Jacobs Jr., and K. Silventoinen, "Comparison of body mass index, waist circumference, and waist/hip ratio in predicting incident diabetes: a meta-analysis," Epidemiologic Reviews, vol. 29, no. 1, pp. 115-128, 2007.

[14] K. M. Rexrode, V. J. Carey, C. H. Hennekens et al., "Abdominal adiposity and coronary heart disease in women," Journal of the American Medical Association, vol. 280, no. 21, pp. 1843-1848, 1998.

[15] S. Zhu, Z. Wang, S. Heshka, M. Heo, M. S. Faith, and S. B. Heymsfield, "Waist circumference and obesity-associated risk factors among whites in the third National Health and Nutrition Examination Survey: clinical action thresholds," The American Journal of Clinical Nutrition, vol. 76, no. 4, pp. 743-749, 2002.

[16] V. Mogre, R. Abedandi, and Z. S. Salifu, "Prevalence of obesity and systemic hypertension among diabetes mellitus patients attending an out-patient diabetes clinic in a Ghanaian Teaching Hospital," Diabetes \& Metabolic Syndrome: Clinical Research \& Reviews, vol. 8, no. 2, pp. 67-71, 2014.

[17] V. Mogre, P. P. Mwinlenaa, J. Oladele, and A. Amalba, "Impact of physical activity levels and diet on central obesity among civil servants in Tamale metropolis," Journal of Medical and Biomedical Sciences, vol. 1, no. 2, pp. 1-9, 2012.

[18] V. Mogre, P. P. Mwinlenna, and J. Oladele, "Distorted selfperceived weight status and its associated factors among civil servants in Tamale," Archives of Public Health, vol. 71, no. 1, article 30, 2013.

[19] A. G. Amoah, S. K. Owusu, and S. Adjei, "Diabetes in Ghana: a community based prevalence study in Greater Accra," Diabetes Research and Clinical Practice, vol. 56, no. 3, pp. 197-205, 2002.

[20] A. G. B. Amoah, "Sociodemographic variations in obesity among Ghanaian adults," Public Health Nutrition, vol. 6, no. 8, pp. 751-757, 2003.

[21] V. Mogre, R. Abedandi, and Z. S. Salifu, "Distorted selfperceived weight status and underestimation of weight status in diabetes mellitus type 2 patients," PLoS ONE, vol. 9, no. 4, Article ID e95165, 2014.

[22] WHO, "Definition, diagnosis and classification of diabetes mellitus and its complications. Report of a WHO consultation," WHO, Geneva, Switzerland, 1999.

[23] WHO, Waist Circumference and Waist-Hip Ratio: Report of a WHO Expert Consultation, WHO, Geneva, Switzerland, 2008.

[24] "1999 World health organization-international society of hypertension guidelines for the management of hypertension. Guidelines subcommittee," Journal of Hypertension, vol. 17, no. 2, pp. 151-183, 1999.

[25] N. Nahar, S. Dubey, A. Joshi, S. Phadnis, and V. Sharma, "Association of anthropometric indices of obesity with diabetes, hypertension and dyslipidemia: a study from central India," Indian Journal of Medical Specialities, vol. 3, no. 1, pp. 6-11, 2012.

[26] B. C. Unadike, A. Eregie, and A. E. Ohwovoriole, "Prevalence of hypertension amongst persons with diabetes mellitus in Benin City, Nigeria," Nigerian Journal of Clinical Practice, vol. 14, no. 3 , pp. 300-302, 2011.
[27] M. Ducorps, B. Bauduceau, H. Mayaudon, E. Sonnet, L. Groussin, and C. Castagné, "Prevalence of hypertension in a Black African diabetic population," Archives des Maladies du Coeur et des Vaisseaux, vol. 89, no. 8, pp. 1069-1073, 1996.

[28] C. F. Otieno, V. Vaghela, F. W. Mwendwa, J. K. Kayima, and E. N. Ogola, "Cardiovascular risk factors in patients with type 2 diabetes mellitus in Kenya: levels of control attained at the outpatient diabetic Clinic of Kenyatta National Hospital, Nairobi," East African Medical Journal, vol. 82, supplement 14, pp. S184-S190, 2005.

[29] V. Baskar, D. Kamalakannan, M. R. Holland, and B. M. Singh, "Does ethnic origin have an independent impact on hypertension and diabetic complications?" Diabetes, Obesity and Metabolism, vol. 8, no. 2, pp. 214-219, 2006.

[30] M. Hanefeld, C. Koehler, S. Gallo, I. Benke, and P. Ott, "Impact of the individual components of the metabolic syndrome and their different combinations on the prevalence of atherosclerotic vascular disease in type 2 diabetes: the Diabetes in Germany (DIG) study," Cardiovascular Diabetology, vol. 6, article 13, 2007.

[31] S. H. Saydah, J. Fradkin, and C. C. Cowie, "Poor control of risk factors for vascular disease among adults with previously diagnosed diabetes," Journal of the American Medical Association, vol. 291, no. 3, pp. 335-342, 2004.

[32] K. G. M. M. Alberti, P. Zimmet, and J. Shaw, "Metabolic syndrome-a new world-wide definition. A consensus statement from the International Diabetes Federation," Diabetic Medicine, vol. 23, no. 5, pp. 469-480, 2006.

[33] S. Tamiru and F. Alemseged, "Risk factors for cardiovascular diseases among diabetic patients in southwest Ethiopia," Ethiopian Journal of Health Sciences, vol. 20, no. 2, pp. 121-128, 2010.

[34] D. Maher, L. Waswa, K. Baisley, A. Karabarinde, N. Unwin, and H. Grosskurth, "Distribution of hyperglycaemia and related cardiovascular disease risk factors in low-income countries: a cross-sectional population-based survey in rural Uganda," International Journal of Epidemiology, vol. 40, no. 1, pp. 160-171, 2011.

[35] G. A. Shayo and F. M. Mugusi, "Prevalence of obesity and associated risk factors among adults in Kinondoni municipal district, Dar es Salaam Tanzania," BMC Public Health, vol. 11, article 365, 2011.

[36] K. W. Wahab, M. U. Sani, B. O. Yusuf, M. Gbadamosi, A. Gbadamosi, and M. I. Yandutse, "Prevalence and determinants of obesity-a cross-sectional study of an adult Northern Nigerian population," International Archives of Medicine, vol. 4, no. 1, article 10, 2011.

[37] M. E. Díaz Sánchez, S. Jiménez Acosta, R. G. García Roche, M. Bonet Gorbea, and I. Wong Ordóñez, "Overweight, obesity, central adiposity and associated chronic diseases in cuban adults," MEDICC Review, vol. 11, no. 4, pp. 23-28, 2009.

[38] T. Puoane, K. Steyn, D. Bradshaw et al., "Obesity in South Africa: the South African Demographic and Health Survey," Obesity Research, vol. 10, no. 10, pp. 1038-1048, 2002.

[39] C. U. Odenigbo, O. C. Oguejiofor, and U. M. Odenigbo, "Prevalence of abdominal obesity in senior civil servants in Asaba, Nigeria," Tropical Journal of Medical Research, vol. 12, no. 2, pp. 1-3, 2008.

[40] P. M. Janiszewski, I. Janssen, and R. Ross, "Does waist circumference predict diabetes and cardiovascular disease beyond commonly evaluated cardiometabolic risk factors?" Diabetes Care, vol. 30, no. 12, pp. 3105-3109, 2007. 
[41] R. Ayah, M. D. Joshi, R. Wanjiru et al., "A population-based survey of prevalence of diabetes and correlates in an urban slum community in Nairobi, Kenya," BMC Public Health, vol. 13, no. 1, article 371, 2013.

[42] S. Mehdad, A. Hamrani, K. El Kari et al., "Body mass index, waist circumference, body fat, fasting blood glucose in a sample of Moroccan adolescents aged 11-17 years," Journal of Nutrition and Metabolism, vol. 2012, Article ID 510458, 7 pages, 2012.

[43] D. S. Freedman, M. K. Serdula, S. R. Srinivasan, and G. S. Berenson, "Relation of circumferences and skinfold thicknesses to lipid and insulin concentrations in children and adolescents: the Bogalusa Heart Study," The American Journal of Clinical Nutrition, vol. 69, no. 2, pp. 308-317, 1999.

[44] M. I. Goran and B. A. Gower, "Abdominal obesity and cardiovascular risk in children," Coronary Artery Disease, vol. 9, no. 8, pp. 483-487, 1998.

[45] N. C. de Souza and E. P. de Oliveira, "Sagittal abdominal diameter shows better correlation with cardiovascular risk factors than waist circumference and BMI," Journal of Diabetes \& Metabolic Disorders, vol. 12, p. 41, 2013. 


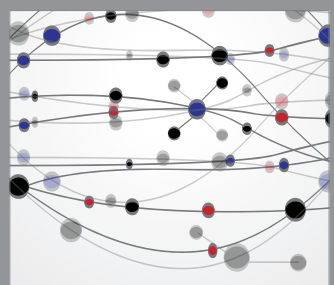

The Scientific World Journal
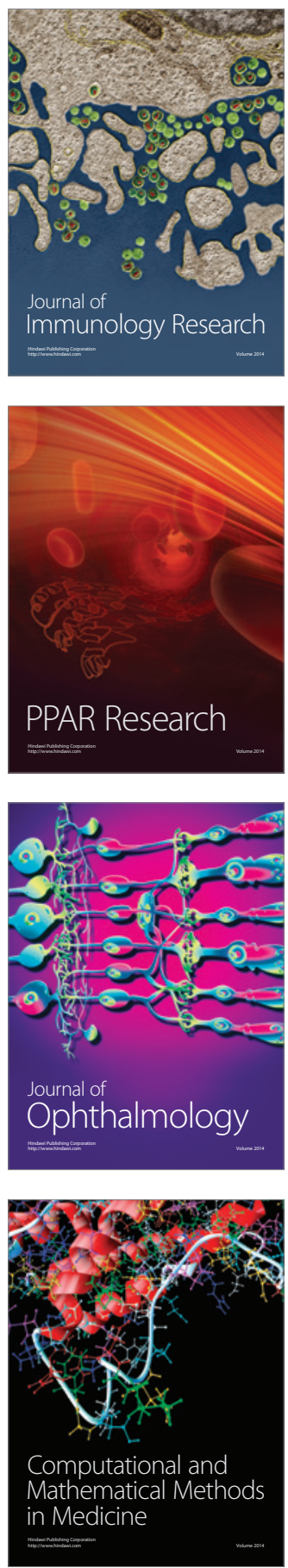

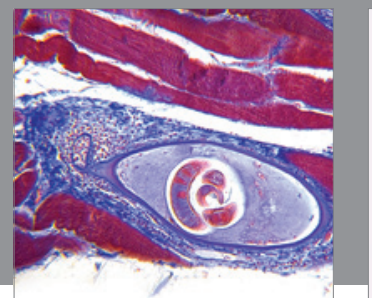

Gastroenterology

Research and Practice
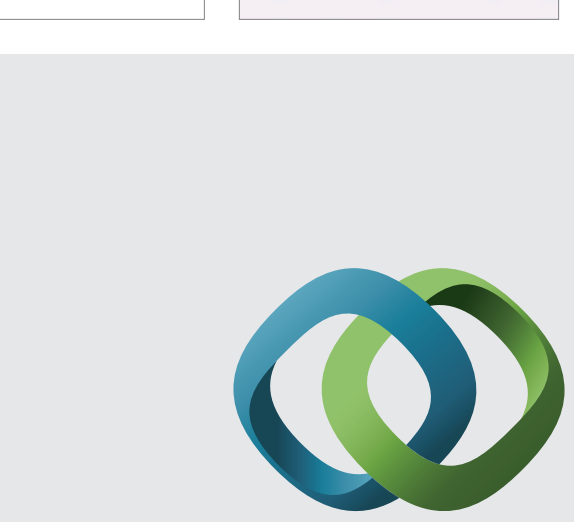

\section{Hindawi}

Submit your manuscripts at

http://www.hindawi.com
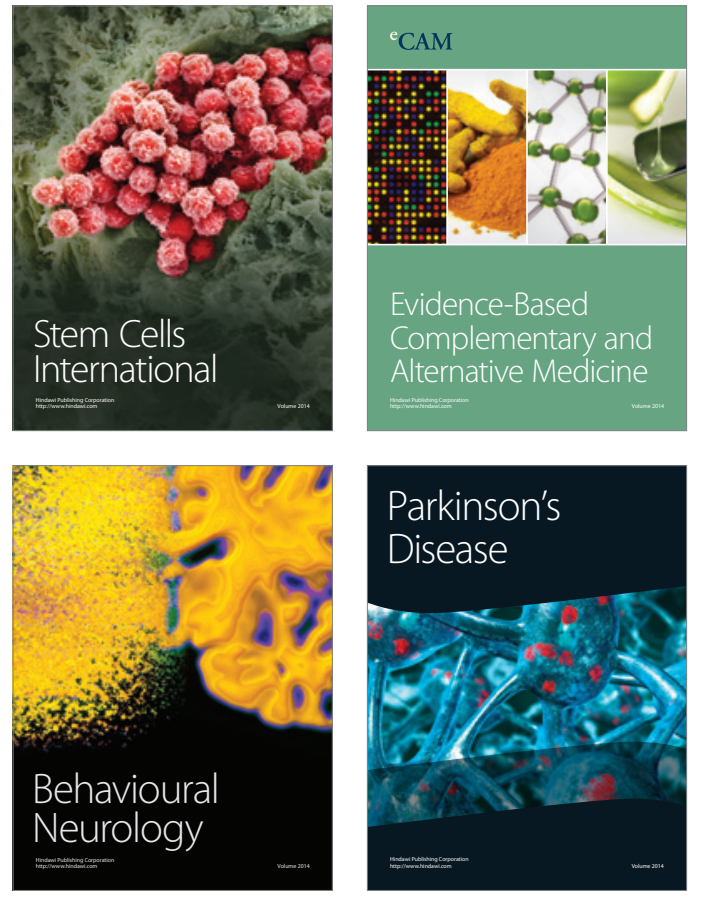
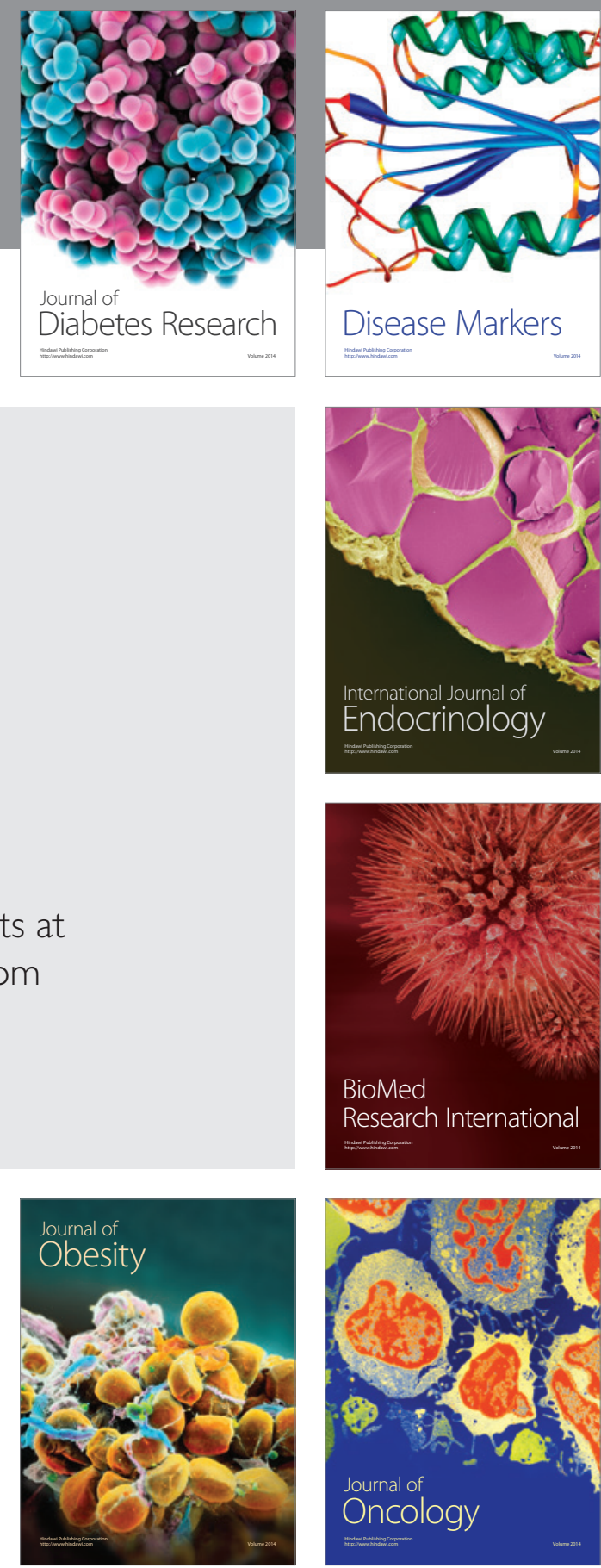

Disease Markers
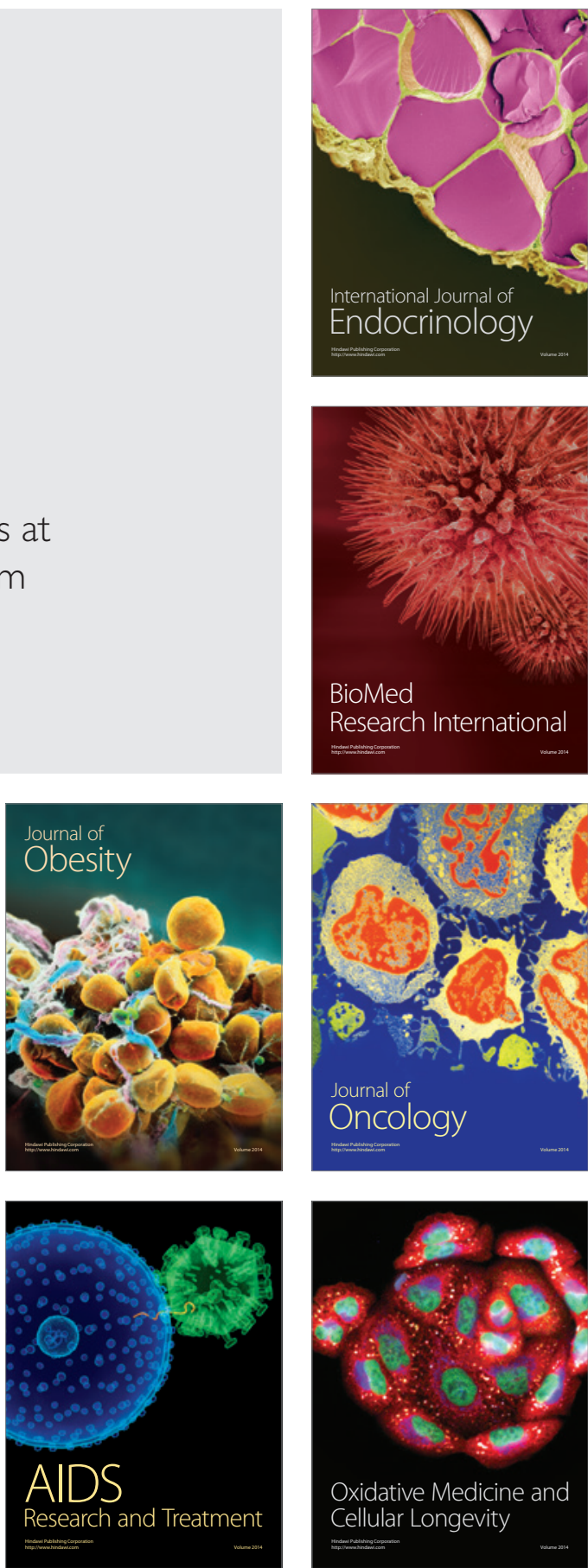